\title{
Prognostic Value of Inferior Shift of P wave Axis after Catheter Ablation for Longstanding Persistent Atrial Fibrillation based on Dallas Lesion Set Including Anterior Line
}

Dong Geum Shin, MD1; Tae-Hoon Kim, MD'; Hyunmin Jeong, BScㄹ; Alexander Kim, MD1; Jae-Sun Uhm, MD, PhD1; Boyoung Joung, MD, PhD1; Moon-Hyoung Lee, MD, PhD1; Chun Hwang, MD2; Hui-Nam Pak, MD, PhD 1

${ }^{1}$ Yonsei University Health System, Seoul, Republic of Korea, ${ }^{2}$ Utah Valley Medical Center, Provo, UT, U.S.A.
Received: February 13, 2017

Revision Received: March 19, 2017 Accepted: March 30, 2017

Correspondence: Hui-Nam Pak, MD, PhD Yonsei University Health System, 50 Yonsei-ro, Seodaemun-gu, Seoul 03722, Republic of Korea Tel: +82-2-2228-8459 Fax: +82-2-393-2041 E-mail: hnpak@yuhs.ac

\section{ABSTRACT}

Background and Objectives: Although an anterior linear ablation is an effective lesion set in radiofrequency catheter ablation (RFCA) for longstanding persistent atrial fibrillation (L-PeAF), its durability for bidirectional block (BDB) is only about $60 \%$ at repeat procedure. We hypothesized that changes in electrocardiogram (ECG) may predict an anterior line block state and the clinical outcome of L-PeAF ablation.

Subjects and Methods: We studied 304 L-PeAF patients (77\% male, $60 \pm 10 y r s$ ), who consistently underwent RFCA Dallas lesion set (circumferential pulmonary vein isolation, posterior box lesion, and anterior line) protocol with subsequent comparison of pre-procedural and post-procedural $P$ wave axes, and one year follow-up $(n=205)$ sinus rhythm (SR) ECGs.

Results: 1 . P wave axis shifted inferiorly at immediate post-procedure $(p<0.001)$, and was independently correlated with BDB of anterior line ( $\beta=10.4$, 95\% confidence interval $[\mathrm{Cl}] 2.79-17.94, p=0.008$ ). 2. The degree of post-procedural inferior shift of $P$ wave axis did not reflect clinical recurrence within one-year $(n=205, p=0.923)$, potentially due to conduction recovery of an anterior line. However, among 160 patients without clinical recurrence within one-year, $\mathrm{P}$ wave axis at one-year ECG was independently associated with very late recurrence of $A F$ after one-year $(n=160$, hazard ratio [HR]

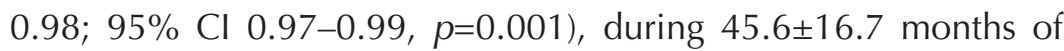
follow-up. 3. Among 22 patients who underwent repeat procedures, $P$ wave axis shift was more significant in patients with maintained BDB of an anterior line than in those without ( $p=0.015)$.

Conclusion: An inferior shift of $P$ wave axis reflects the achievement and the maintenance of an anterior line BDB, and is associated with better long-term clinical outcome after catheter ablation for L-PeAF based on Dallas lesion set.

Key Words: - P wave -Longstanding Persistent Atrial Fibrillation - Catheter Ablation -Anterior Line -Very Late Rrecurrence 


\section{Introduction}

Radiofrequency catheter ablation (RFCA) has become an accepted standard rhythm control treatment option in antiarrhythmic drug (AAD) resistant atrial fibrillation (AF) management. ${ }^{1}$ Persistent AF (PeAF) accompanies significant arrhythmic substrates and a higher AF burden. Current technology, however, such as an irrigated tip ablation catheters or three-dimensional electroanatomical mapping systems, have improved rhythm control outcomes remarkably. A PeAF catheter ablation, in terms of reducing the AF burden, is more effective than AAD. ${ }^{2}$ We previously reported that an anterior linear ablation is an effective strategy in RFCA for PeAF, ${ }^{3}$ mimicking the Dallas lesion set of surgical mini-maze procedure. ${ }^{4}$ However, catheter ablation for longstanding PeAF (L-PeAF) remains a challenge, owing to the long-term recurrence of $\mathrm{AF}^{5}$ and limited long-term clinical outcomes of linear ablation.

Furthermore, L-PeAF is vulnerable to AF progression, ${ }^{6}$ even following successful catheter ablation. An AF recurrence prediction, therefore, employing simple non-invasive techniques, remains an unresolved clinical need in patients undergoing AF ablation. P wave analysis using standard surface 12-lead electrocardiography (ECG) is a simple and cost-effective modality for determining the prognosis of AF. We recently reported that low $\mathrm{P}$ wave amplitude in lead I with displaced interatrial conduction, ${ }^{7}$ and prolonged PR interval, ${ }^{8}$ are associated with a higher clinical recurrence rate of AF after catheter ablation. However, the clinical value of ECG in the context of ablation for $\mathrm{AF}$ is not well-established thus far, and the study populations in most studies included patients with paroxysmal AF (PAF).,9 Therefore, we hypothesized that there would be a change in $\mathrm{P}$ wave morphology on ECG in association with linear ablation after catheter ablation in L-PeAF patients, and that those changes would have clinical implications. The purpose of this study was to determine long-term $\mathrm{P}$ wave changes after RFCA, their relationship with bidirectional block $(\mathrm{BDB})$ of the linear ablation, and their prediction power for very late recurrence of AF in patients with L-PeAF.

\section{Subjects and Methods}

\section{Study design}

This study protocol was approved by the Institutional Review Board of Yonsei University Health System, and complied with the Declaration of Helsinki. All patients in this study signed a written informed consent form provided for their inclusion in the Yonsei AF ablation cohort (registered at clinicaltrials.gov with NCT2138695). Among 1,319 consecutive patients who underwent RFCA between March 2009 and December 2013, we included 587 patients with L-PeAF. L-PeAF was defined as AF lasting longer than one year, ${ }^{6}$ and AF duration was determined using ECG findings, and was not based on the presence of symptoms alone. Each patient underwent RFCA for symptomatic AF refractory to pharmacologic management. Among the 587 patients with L-PeAF, we selected and analyzed 304 patients with the same ablation lesion set (posterior box lesion and anterior linear ablations; Dallas lesion set), no history of previous RFCA or cardiac surgery, and no valvular or structural heart diseases (Figure 1). These 304 patients had pre-procedural and immediate post-procedural ECG parameters analyzed. Most of the included patients with L-PeAF had pre-procedural sinus rhythm ECG, because they underwent electrical cardioversion. Catheter ablation was not recommended, if sinus rhythm could not be restored with cardioversion. We additionally analyzed ECG parameters in 205 patients with sinus rhythm ECGs at one year post-ablation. This analysis was performed after excluding patients with less than 12 months follow-up $(\mathrm{n}=27)$, and patients without a discernible sinus rhythm ECGs one year after the procedure $(n=72)$. After excluding patients with sinus rhythm but clinical recurrence $(n=45)$ among the 205 patients, 160 RFCA patients with one-year ECG sinus rhythm history but without clinical recurrence were further evaluated for the very late recurrence presence, during an extended follow-up period.

\section{Measurement of electrocardiography parameters}

A mean duration for ECG documented AF was $60.3 \pm 99.7$ months. Standard 12-lead ECGs (GE Healthcare, Marquette, MAC5500, Waukesha, WI, USA) were acquired after restoring sinus rhythm by electrical cardioversion $(2.47 \pm 3.08$ months before catheter ablation), immediately after catheter ablation, and 


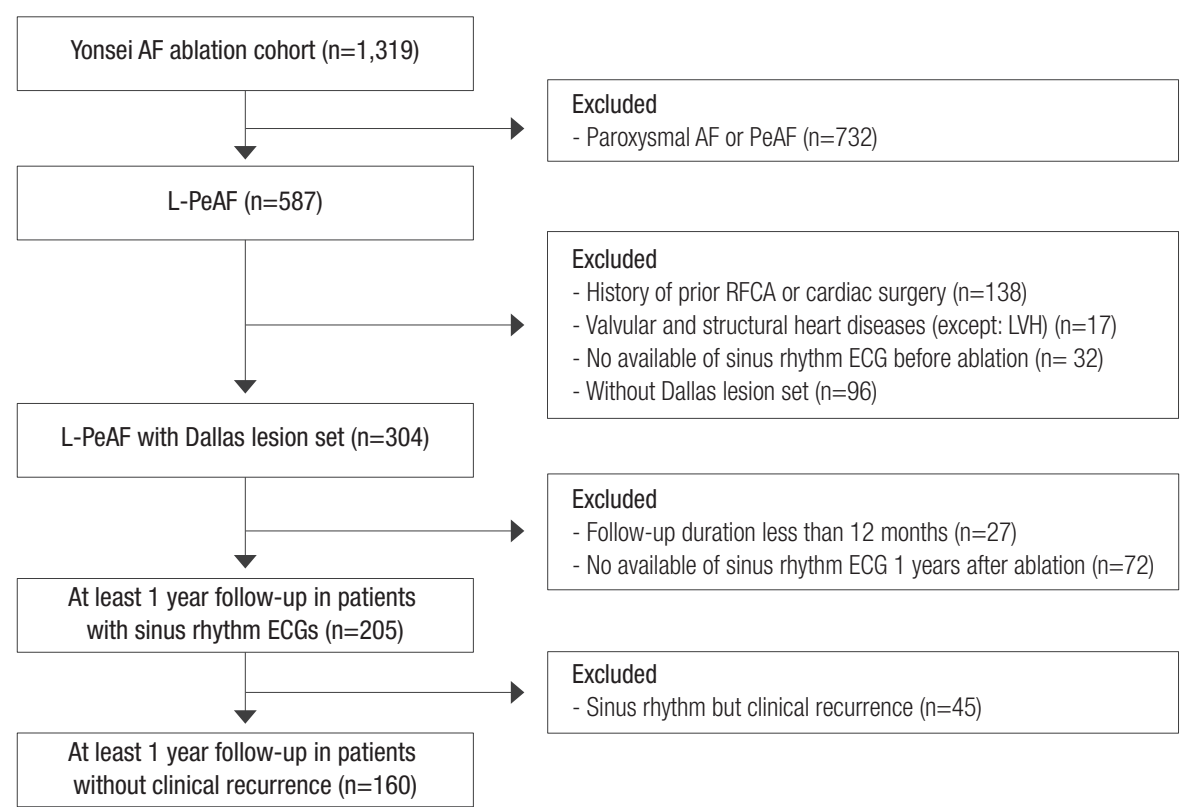

Figure 1. Enroll of the study population.

$A A D$, antiarrhythmic drug; $A F$, atrial fibrillation; ECG, electrocardiography; LVH, left ventricle hypertrophy;

L-PeAF, longstanding persistent atrial fibrillation; RFCA, radiofrequency catheter ablation

at one year after the procedure. The sweep speed was $25 \mathrm{~mm} / \mathrm{s}$ and the device was calibrated to $1 \mathrm{mV} / \mathrm{cm}$. The heart rate, PR interval, and $\mathrm{P}$-axis were automatically calculated with the available equipment. All $\mathrm{P}$ wave measurements were conducted by a single technician who was blinded to the clinical data. The correlation coefficient for the intra-class correlation was 0.96 .

\section{Radiofrequency catheter ablation}

Details regarding electrophysiological mapping, RFCA technique and strategy have been described in previous studies. ${ }^{10}$ In brief, an open irrigation 3.5-mm-tip deflectable catheter (Celsius, Biosense-Webster, Johnson \& Johnson Inc. Diamond Bar, CA, USA; Coolflex, St. Jude Medical Inc., Minnetonka, MN, USA.; 25-35 W) with threedimensional electroanatomic mapping abilities (CARTO3, Johnson \& Johnson Inc. Diamond Bar, CA, USA; NavX, St. Jude Medical, Inc., Minnetonka, MN, USA) was used for the RFCA. We created a standard Dallas lesion set by adding a roof line, a posterior-inferior line, an anterior line, and a cavo-tricuspid isthmus line, following circumferential pulmonary vein isolation (CPVI). Each linear line $\mathrm{BDB}$ was confirmed by differential pacing maneuvers and activation mapping in all patients. ${ }^{11}$ Additional ablations were performed to generate $\mathrm{BDBs}$ of these lines in cases in which BDBs of linear ablation lines were not achieved. However, ablation lines were kept unblocked to avoid collateral damage were not able to achieve linear ablation $\mathrm{BDBs}$ after three attempts. If there were mappable $\mathrm{AF}$ triggers or atrial premature beats (APCs) with isoproterenol infusion $(5 \mu \mathrm{g} / \mathrm{min})$, we carefully mapped and ablated those non-PV foci as much as possible. All RFCA procedures were conducted by two operators with more than 10 years of experience, in strict accordance to the aforementioned protocol.

\section{Follow-up after ablation}

All patients were monitored with continuous ECG overnight and discharged the day after the procedure. Of the total number of patient, $24.6 \%$ were discharged with $\mathrm{AADs}$ due to high chance of $\mathrm{AF}$ recurrence. $\mathrm{AADs}$ were discontinued if there was no evidence of AF/AT recurrence after the third month Holter. All patients were followed up with at the outpatient clinic at one, three, six, and 12 months, and every six months thereafter or whenever symptoms occurred after the ablation. Rhythm follow-ups every visit by ECG 
and Holter monitoring (24 hour) and/or event recording were conducted at three- and six-month intervals during the first year and every six months thereafter, according to the 2012 Heart Rhythm Society/EHRA/European Cardiac Arrhythmia Society Expert Consensus Statement guidelines. ${ }^{12}$ In addition, Holter monitoring or event recording was used in an attempt to diagnose arrhythmia, if the patient presented with palpitations. We defined recurrence of $\mathrm{AF}$ as any episode of $\mathrm{AF}$ or atrial tachycardia lasting longer than 30 seconds. ${ }^{12}$ Any ECG documentation of AF recurrence after three months was diagnosed as clinical recurrence. An episode of recurrent AF occurring more than a year after ablation was defined as a very late recurrence. In $\mathrm{AF} /$ atrial tachycardia recurrence patients, rhythm control was managed by $\mathrm{AADs}$ with or without cardioversion. It was our practice to recommend a second ablation procedure to these patients, unless sinus rhythm was maintained with AADs.

\section{Statistical analysis}

Continuous variables were reported as mean \pm standard deviation and analyzed using independent t-tests or the Mann-Whitney $\mathrm{U}$ test. The normality was determined using the Kolmogorov-Smirnov goodness-of-fit test. Categorical variables were reported as counts and proportions, and were analyzed using Pearson's chi-square tests or Fisher's exact tests, as appropriate. Differences in ECG parameters before and after the RFCA were tested for, using the paired $t$-test. Multivariate linear regression analysis was used to identify predictors of $\mathrm{P}$ wave axis change. Variables found to be statistically significant on the univariate analysis were further analyzed using multivariate Cox regression analysis to evaluate the independent predictors of AF very late recurrence. The cutoff value for $P$ wave axis change best differentiated between patients with or without an anterior line BDB, and with or without very late recurrence, were determined by using receiver-operating characteristic (ROC) curves. Kaplan-Meier analyses with log rank tests were used to compare AF recurrence-free survival over time, according to $\triangle \mathrm{P}$-axis. The SPSS statistical package (SSPS Inc., Chicago, IL, USA) was used to perform all statistical evaluations. A $p$-value $\leq 0.05$ was considered statistically significant.

\section{Results}

P wave axis inferior shift after anterior linear ablation
Table 1. Baseline clinical characteristics of L-PeAF patients

\begin{tabular}{|c|c|}
\hline Age, years & $60.35 \pm 10.19$ \\
\hline Sex, male & $235(77.3)$ \\
\hline $\mathrm{BSA}, \mathrm{m}^{2}$ & $1.82 \pm 0.18$ \\
\hline $\mathrm{BMI}, \mathrm{kg} / \mathrm{m}^{2}$ & $25.15 \pm 2.92$ \\
\hline AF duration, months & $60.3 \pm 99.7$ \\
\hline \multicolumn{2}{|l|}{ Medical history } \\
\hline Heart failure & $43(14.1)$ \\
\hline Hypertension & $167(54.9)$ \\
\hline Diabetes mellitus & $60(19.8)$ \\
\hline Stroke & $33(10.9)$ \\
\hline Vascular disease & $57(18.8)$ \\
\hline \multicolumn{2}{|l|}{ Score system } \\
\hline $\mathrm{CHADS}_{2}$ & $1.23 \pm 1.14$ \\
\hline $\mathrm{CHA}_{2} \mathrm{DS}_{2}-\mathrm{VASC}$ & $2.01 \pm 1.65$ \\
\hline \multicolumn{2}{|l|}{ Echocardiography } \\
\hline LA diameter (AP), mm & $45.03 \pm 5.45$ \\
\hline $\mathrm{LAVI}, \mathrm{mL} / \mathrm{m}^{2}$ & $43.61 \pm 12.13$ \\
\hline LVEDD, mm & $50.63 \pm 4.99$ \\
\hline LVEF, \% & $61.07 \pm 9.17$ \\
\hline
\end{tabular}

Numbers in parenthesis represent percentage.

$\mathrm{AF}$, atrial fibrillation; BMI, body mass index; $\mathrm{BSA}$, body surface area; $\mathrm{CHADS}_{2}$, congestive heart failure, hypertension, age $\geq 75$, diabetes mellitus, and prior stroke or transient ischemic attack (doubled); $\mathrm{CHA}_{2} \mathrm{DS}_{2}$ VASC, congestive heart failure, hypertension, age $\geq 75$ (doubled), diabetes mellitus, and prior ischemic stroke, transient ischemic attack or thromboembolism (doubled), vascular disease, age 65 to 74, sex category (female); HAS-BLED, hypertension, abnormal renal//iver function, stroke, bleeding tendency or predisposition, labile INR, elderly (e.g. >65), drugs (e.g., aspirin, clopidogrel, or non-steroidal anti-inflammatory drugs), alcohol abuse; LA, left atrium; LAVI, LA volume index; L-PeAF, longstanding persistent atrial fibrillation; LV, left ventricle; LVEDD, LV end diastolic dimension; LVEF, LV ejection fraction

Table 1 shows the baseline characteristics of the overall study population. The $\mathrm{P}$ wave axis shows inferior shift after ablation, when pre- and immediate post-ablation were compared $\left(49.38^{\circ}\right.$ [46.57 52.19 $]$ vs. $\left.67.59^{\circ}\left[65.01 \sim 70.14^{\circ}\right], p<0.001\right)$. The BDB of linear ablation was confirmed anterior line in $68.4 \%$, roof line in $86.8 \%$ and posterior-inferior line in $41.4 \%$ patients who 
Table 2. Change of $P$ wave axis according to bidirectional block of linear ablation

\begin{tabular}{lcccc}
\hline & Bidirectional block & $\Delta$ P wave axis* & Z-score & P-value \\
\hline Anterior line & Incomplete (78) & $9.40(3.96-14.83)$ & -3.09 & 0.002 \\
\multirow{2}{*}{ Roof line } & Complete (208) & $20.22(16.40-24.04)$ & & \\
& Incomplete (24) & $5.50(-7.76$ to 18.76) & -1.88 & 0.060 \\
Posterior-inferior line & Complete (264) & $18.16(14.92-21.39)$ & & 0.805 \\
& Incomplete (140) & $18.23(13.74-22.72)$ & -0.25 & \\
\hline
\end{tabular}

${ }^{*} \triangle \mathrm{P}$ wave axis $=\mathrm{P}$ wave axis immediate post-RFCA $-\mathrm{P}$ wave axis PRE-RFCA $_{\text {R }}$

RFCA, radiofrequency catheter ablation

Table 3. Linear regression analysis for clinical variables predictive of the change of $P$ wave axis

\begin{tabular}{|c|c|c|c|c|}
\hline \multirow{2}{*}{$\Delta \mathrm{P}$-wave axis* } & \multicolumn{2}{|c|}{ Univariate analysis } & \multicolumn{2}{|c|}{ Multivariate analysis* } \\
\hline & B $(95 \%$ Cl) & $P$-value & B $(95 \%$ Cl) & $P$-value \\
\hline Age & $-0.16(-0.48$ to 0.15$)$ & 0.311 & $-0.25(-0.58$ to 0.08$)$ & 0.131 \\
\hline Sex, male & 0.44 (-7.09 to 7.97$)$ & 0.909 & 2.36 (-5.23 to 10.24$)$ & 0.557 \\
\hline BMI, kg/m² & $0.27(-0.81$ to 1.34$)$ & 0.623 & & \\
\hline \multicolumn{5}{|l|}{ Echocardiography } \\
\hline LA diameter (AP), mm & $0.18(-0.40$ to 0.75$)$ & 0.595 & & \\
\hline LA volume index, $\mathrm{mL} / \mathrm{m}^{2}$ & $0.15(-0.11$ to 0.42$)$ & 0.215 & & \\
\hline \multicolumn{5}{|l|}{ Complete bidirectional block } \\
\hline Anterior line & $10.82(3.77-17.88)$ & 0.003 & $10.36(2.79-17.94)$ & 0.008 \\
\hline Roof line & $12.66(1.28-24.03)$ & 0.029 & 10.66 (-1.92 to 23.24) & 0.097 \\
\hline Posterior inferior line & $2.26(-4.33$ to 8.85$)$ & 0.500 & & \\
\hline
\end{tabular}

${ }^{*} \triangle \mathrm{P}$ wave axis $=\mathrm{P}$ wave axis immediate post-RFCA $-\mathrm{P}$ wave axis PRE-RFCA

$\mathrm{BMI}$, body mass index; $\mathrm{Cl}$, confidence interval; LA, left atrium; RFCA, radiofrequency catheter ablation

underwent a de novo procedure, respectively. Compared with the changes in $\mathrm{P}$ wave axis by $\mathrm{BDB}$ in each linear ablation set that were evaluated, $\mathrm{p}$ wave axis was significantly more inferiorly shifted in cases of $\mathrm{BDB}$ of an anterior line $\left(20.22^{\circ}\left[16.40 \sim 24.04^{\circ}\right]\right.$ vs. $9.40^{\circ}\left[3.96 \sim 14.83^{\circ}\right], p=0.002$; Table 2). Table 3 summarizes the linear regression analysis for clinical variables associated with $\mathrm{P}$-wave axis change. In multivariate analysis, $\mathrm{BDB}$ of an anterior line ( $B=10.4$, 95\% CI 2.79-17.94, $p=0.008$ ) was independently associated with $\mathrm{P}$ wave axis change. In the receiver-operating

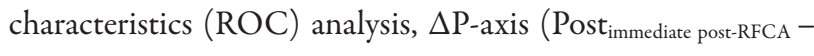
$\left.\operatorname{Pre}_{\text {pre-RFAA }}\right) 8.5^{\circ}$ was well-correlated with an anterior line BDB acute achievement (AUC=0.619, 95\% CI 0.547-0.690, $p=0.002$; Figure 2A).

P wave axis shift and AF recurrence after catheter ablation for persistent AF

Among the 205 patients who had one-year follow-up SR ECG, 
Table 3. Univariate and multivariate Cox regression analysis for predictors of very late recurrence in L-PeAF patients

\begin{tabular}{|c|c|c|c|c|}
\hline \multirow{2}{*}{$\Delta P$ wave axis* } & \multicolumn{2}{|c|}{ Univariate analysis } & \multicolumn{2}{|c|}{ Multivariate analysis* } \\
\hline & $\mathrm{HR}(95 \% \mathrm{Cl})$ & $P$-value & $\mathrm{HR}(95 \% \mathrm{Cl})$ & $P$-value \\
\hline Age & $0.993(0.963-1.023)$ & 0.631 & & \\
\hline Sex, male & $0.914(0.430-1.943)$ & 0.816 & & \\
\hline $\mathrm{BMI}, \mathrm{kg} / \mathrm{m}^{2}$ & $1.082(0.967-1.210)$ & 0.171 & & \\
\hline \multicolumn{5}{|l|}{ Medical history } \\
\hline Heart failure & $0.734(0.260-2.071)$ & 0.559 & & \\
\hline Hypertension & $0.838(0.454-1.550)$ & 0.574 & & \\
\hline Diabetes mellitus & $1.430(0.655-3.123)$ & 0.369 & & \\
\hline Stroke & $1.409(0.588-3.381)$ & 0.442 & & \\
\hline Vascular disease & $1.304(0.599-2.836)$ & 0.504 & & \\
\hline \multicolumn{5}{|l|}{ Echocardiography } \\
\hline LA diameter (AP), mm & $1.006(0.953-1.063)$ & 0.822 & & \\
\hline $\mathrm{LA}$ volume index, mL/m² & $1.013(0.985-1.043)$ & 0.359 & & \\
\hline \multicolumn{5}{|l|}{ Incomplete bidirectional block } \\
\hline Anterior line & $1.236(0.618-2.470)$ & 0.549 & & \\
\hline Roof line & $2.369(0.986-5.687)$ & 0.054 & $2.375(0.931-6.062)$ & 0.070 \\
\hline Posterior-inferior line & $1.242(0.656-2.352)$ & 0.506 & & \\
\hline \multicolumn{5}{|l|}{ 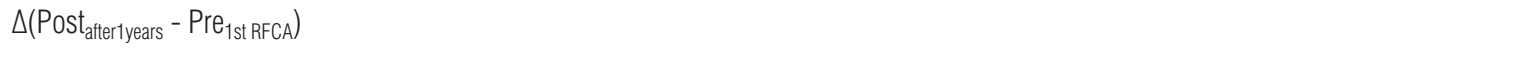 } \\
\hline Heart rate & $0.986(0.963-1.010)$ & 0.254 & & \\
\hline PR interval & $0.996(0.988-1.005)$ & 0.369 & & \\
\hline P-axis & $0.984(0.975-0.994)$ & 0.002 & $0.983(0.973-0.993)$ & 0.001 \\
\hline
\end{tabular}

*Age, sex and BMI adjusted

$\mathrm{BMI}$, body mass index; $\mathrm{Cl}$, confidence interval; LA, left atrium; RFCA, radiofrequency catheter ablation

significant differences existed between the pre- and one-year postablation ECG findings. The mean heart rate significantly increased (60.01 bpm [58.63-61.40 bpm] vs. $67.82 \mathrm{bpm}$ [66.01$69.64 \mathrm{bpm}], p<0.001)$, and PR interval became shorter (200.31 $\mathrm{ms}$ [195.11-205.52 ms] vs. $183.09 \mathrm{~ms}$ [178.27-187.9 $2 \mathrm{~ms}]$, $p<0.001)$. P wave axes of pre- and post-procedural ECG, and oneyear follow-up ECG, were $51.33^{\circ}\left(48.06 \sim 54.60^{\circ}\right), 66.52^{\circ}$ $\left(63.85 \sim 69.18^{\circ}, p=0.001\right.$ vs. pre-procedure), and $60.74^{\circ}$ (56.93 64.54 $4^{\circ}, p=0.08$ vs. pre-procedure), respectively.

One hundred sixty patients out of the 205 patients (78.0\%) remained in sinus rhythm without clinical recurrence at one-year follow-up (41.9\% [67/160] patients with AAD). Immediate postprocedural $\mathrm{P}$ wave axis inferior shift did not predict clinical recurrence within one year of the procedure (HR 0.99; 95\% CI 0.99-1.01, $\mathrm{p}=0.923$ ), and Kaplan-Meier analysis showed that clinical recurrence of AF was not significantly different according

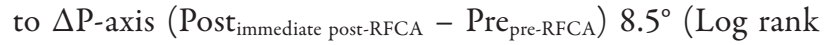
$p=0.460$; Figures $2 \mathrm{~B}$ and $2 \mathrm{C}$ ), potentially due to conduction recovery of an anterior line.

In contrast, among 160 patients without clinical recurrence 
within one year of the procedure, 41 patients (25.6\%) showed very late recurrence of $\mathrm{AF}$ one year after the procedure, and $\mathrm{P}$ wave axis shift seen on a one-year follow-up ECG was independently associated with very late recurrence of $\mathrm{AF}$ ( $\mathrm{HR}$ 0.98 ; $95 \%$ CI $0.97-0.99, p=0.001$ ), during $45.6 \pm 16.7$ months of follow-up (Table 4). The change of $\mathrm{P}$ wave duration and amplitude after ablation procedure did not have a prognostic value (Supplementary Table). ROC curve analysis defined $\triangle \mathrm{P}$-axis $\left(\right.$ Post $\left._{\text {after yyars }}-\mathrm{Pre}_{\mathrm{pre}-\mathrm{RFCA}}\right) 6^{\circ}$ as thresholds for very late recurrence $(\mathrm{AUC}=0.796,95 \% \mathrm{CI} 0.615-0.792, p<0.001$; Figure
2D), and Kaplan-Meier analysis showed a significantly higher very late clinical recurrence of $\mathrm{AF}$ in patients with $\Delta \mathrm{P}$-axis $<6^{\circ}$ (Log rank $p=0.004$ in overall, $p=0.022$ without AAD; Figures $2 \mathrm{E}$ and $2 \mathrm{~F}$ ).

P wave axis predicts bidirectional block state of anterior line in repeat ablation

During the follow-up periods, 39 patients underwent a repeat procedure at $16.8 \pm 10.8$ months, after de novo procedure. Among
ROC curve for anterior line BDB

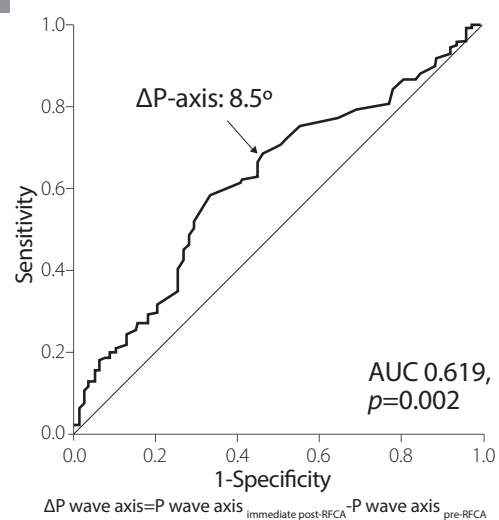

D

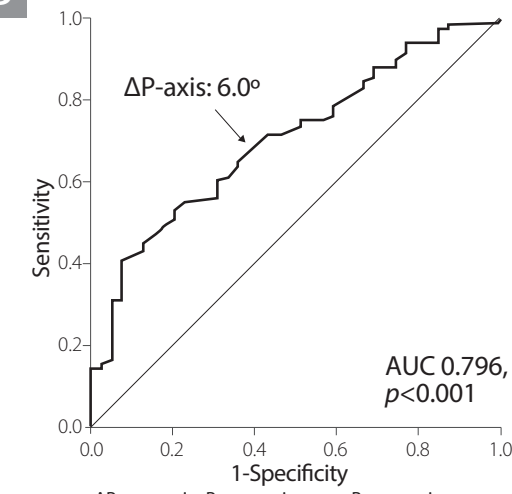

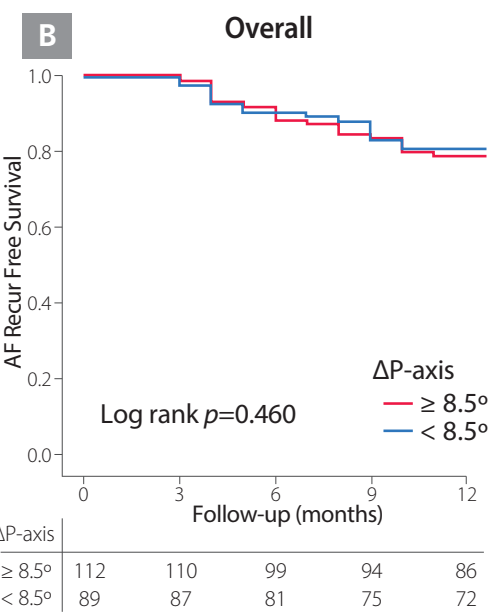
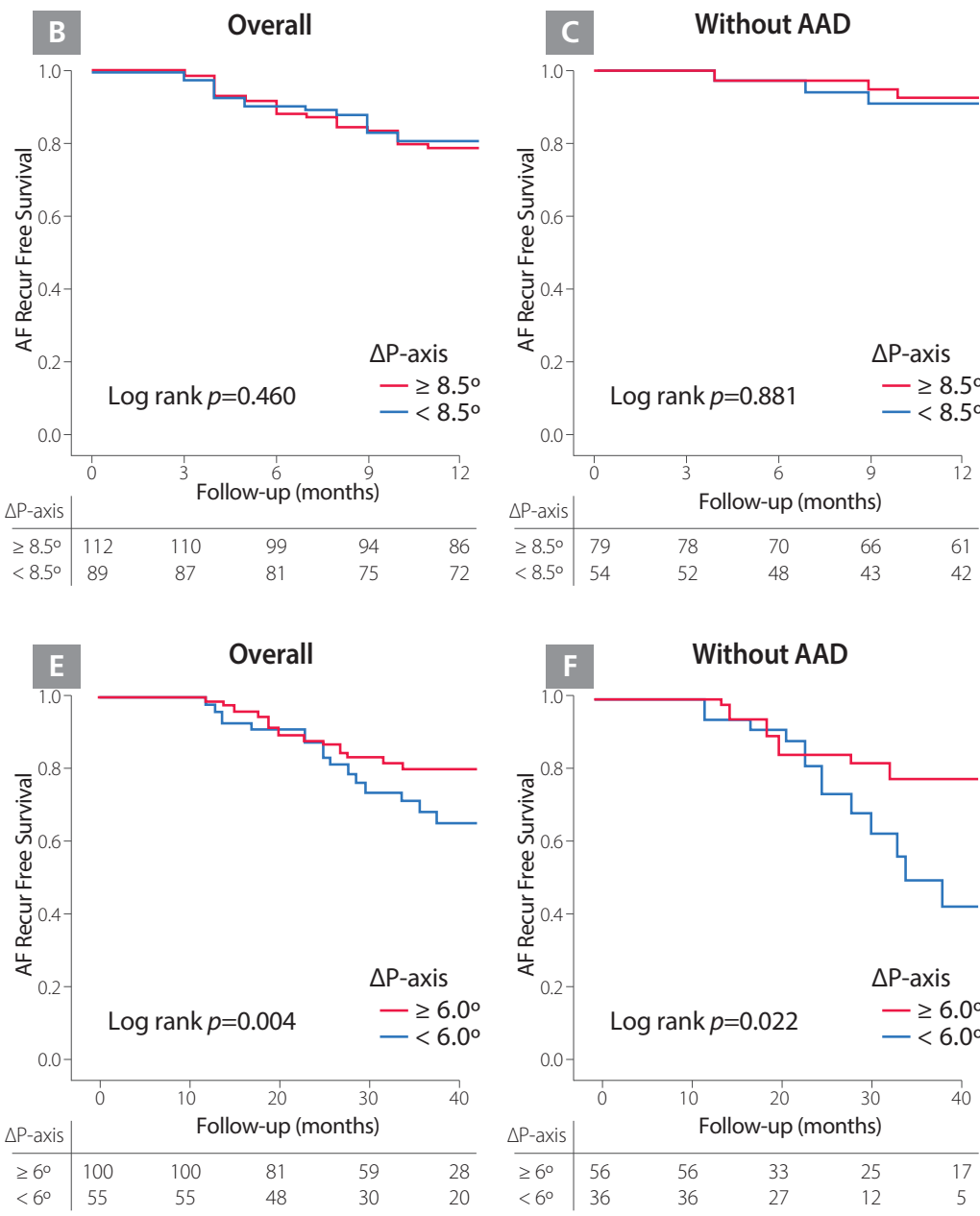

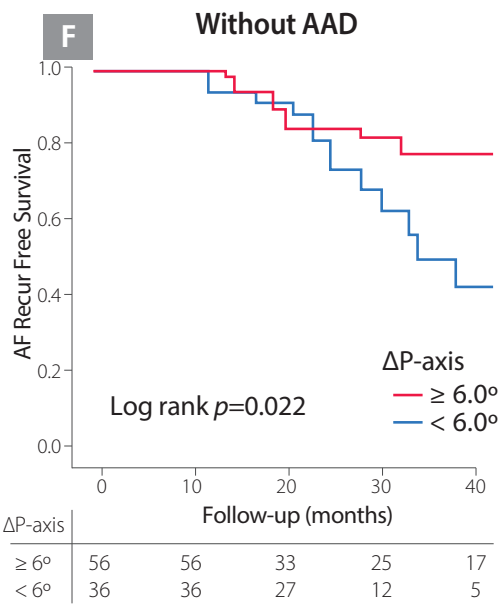

Figure 2. A. ROC curve for the change of $P$ wave axis and the achievement of an anterior line BDB at one day after the procedures. B and $C$. Kaplan-Meier survival curves for clinical recurrence within one year after catheter ablation among the patients who underwent one-year sinus rhythm ECG, depending on the $P$ wave axis change $\geq 8.5^{\circ}$ and $<8.5^{\circ}$ in overall $(B)$ and those without $A A D(C)$. D. ROC curve for the change of $P$ wave axis and very late recurrence one year after the procedure. $\mathrm{E}$ and $\mathrm{F}$. Kaplan-Meier survival curves for very late recurrence after catheter ablation among the patients who underwent one-year sinus rhythm ECG, depending on the $P$ wave axis change $\geq 6.0^{\circ}$ and $<6.0^{\circ}$ in overall (E) and those without $A A D(F)$.

$A A D$, antiarrhythmic drug; $A F$, atrial fibrillation; AUC, area under the curve; BDB, bidirectional block; ECG, electrocardiography; ROC, receiver-operating characteristic 
them, 22 patients achieved an anterior line BDB at the de novo procedure, and 16 of them maintained BDB of anterior linear ablation at redo-mapping (72.7\%). P wave axis at redo-ablation was more inferiorly shifted in patients who maintained an anterior line block $\left(35.14^{\circ}\left[11.30 \sim 58.99^{\circ}\right]\right)$ than in those with a reconnected anterior line $\left(6.50^{\circ}\left[-2.14 \sim 15.14^{\circ}\right], p=0.009\right)$. Compared with $\mathrm{P}$-axis at immediate after de novo procedure, $\mathrm{P}$ wave axis at redo-procedure was significantly different, depending on the BDB state of an anterior line $\left(5.50^{\circ}\left[-0.99 \sim 15.13^{\circ}\right]\right.$ with BDB maintenance vs. $-28.88^{\circ}\left[-4.12 \sim-56.76^{\circ}\right]$ with reconnected $\mathrm{BDB}, \mathrm{p}=0.005$; Figure 3 ).

\section{Discussion}

In this study, we evaluated the clinical and prognostic implications of $\mathrm{P}$ wave axis by comparing sinus rhythm ECGs before and after ablation for L-PeAF with consistent ablation lesion set, including posterior box lesion and anterior linear ablation. An anterior line BDB was independently associated with inferior shifting of the $\mathrm{P}$ wave axis, and maintaining an inferiorly shifted $\mathrm{P}$ wave axis was associated with significantly low very late recurrence rate of $\mathrm{AF}$ one year after the procedure.

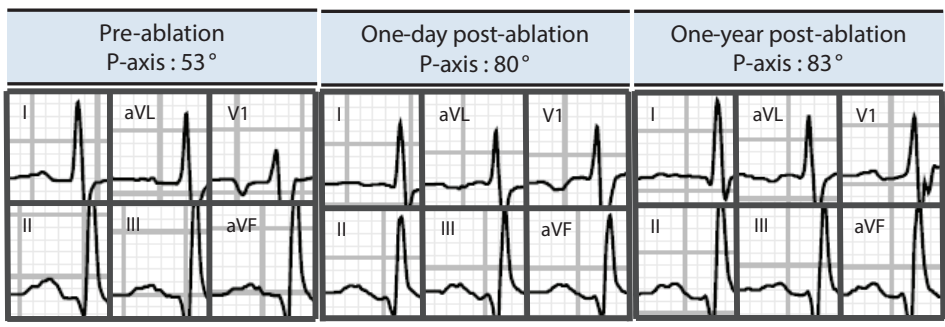

B. Recurrence, but Maintained Bi-directional Block of Anterior Line

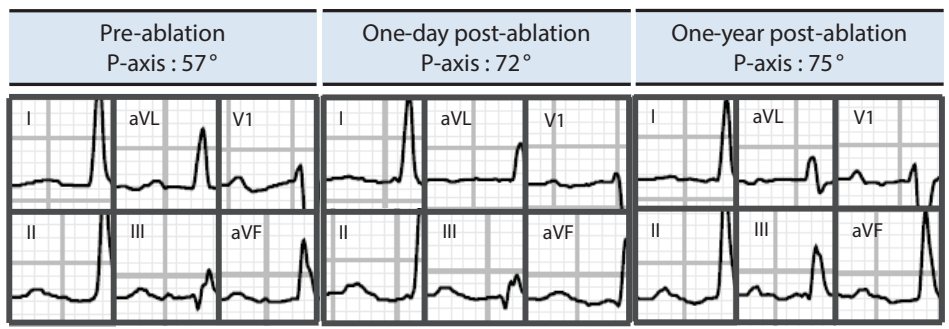

C. Recurrence with Re-connected Bi-directional Block of Anterior Line
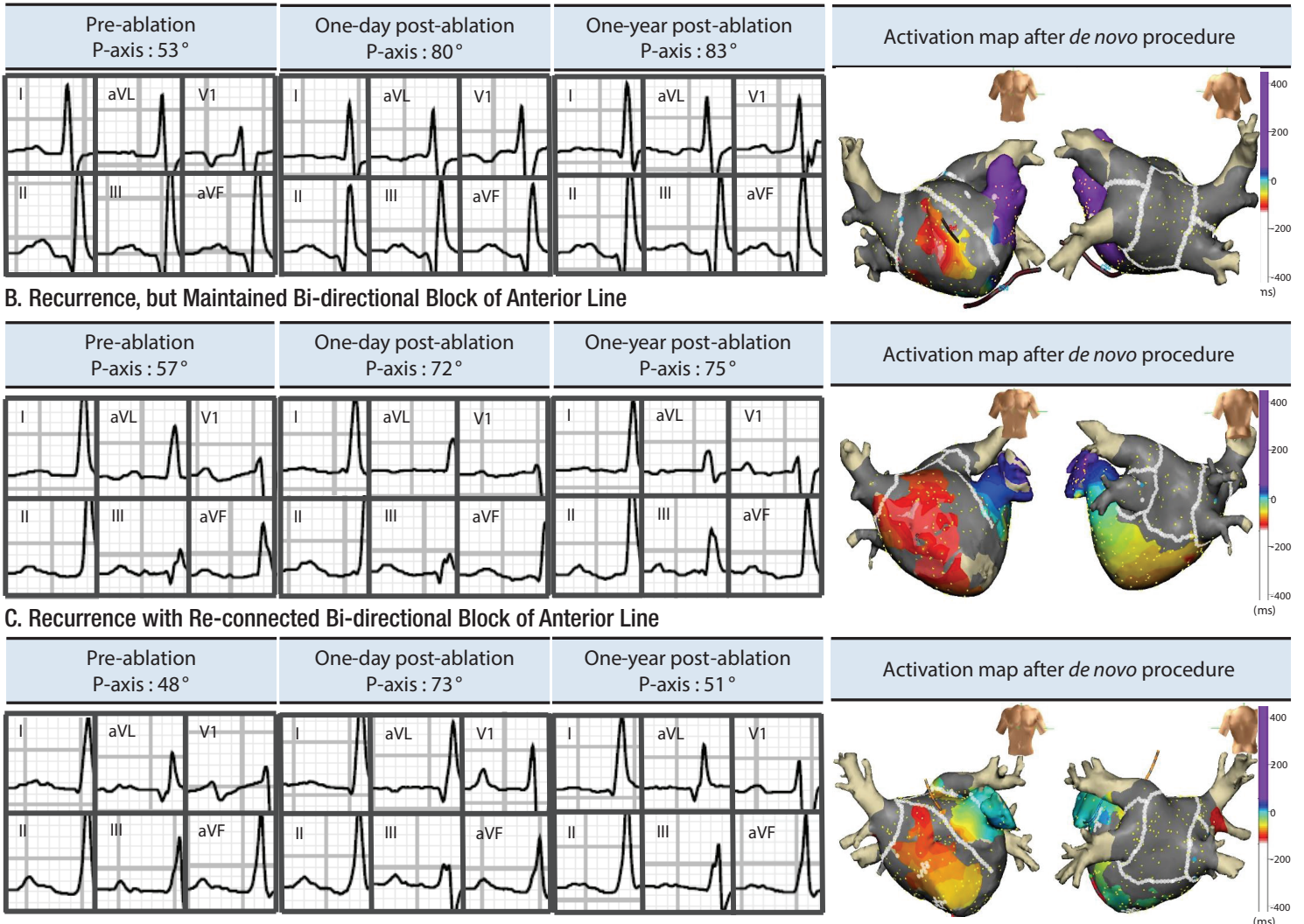

Figure 3. Examples of changes in $\mathrm{P}$ wave axis before, one day after and one year after AF ablation, including anterior line and posterior box lesion. All three patients underwent successful bi-directional blocks of an anterior line during a de novo procedure. Patient A. This patient did not recur AF for 20 months after ablation. Patient B. This patient recurred AF, but anterior line block was maintained at redo procedure, conducted at 17 months after the de novo procedure. Patient C. A previously blocked anterior line was re-connected at the redo-procedure, conducted at 14 months after the de novo ablation.

$\mathrm{AF}$, atrial fibrillation 


\section{Changes of $\mathrm{P}$ wave axis after ablation}

The morphology of the P wave observed using surface ECG represents both atrial electrical activation and possible changes in some pathological conditions. ${ }^{13} \mathrm{AF}$ catheter ablation may result in altered impulse conduction in the atrium, and after linear ablation, especially. Previous studies comparing post-AF ablation ECG have reported changes in P wave duration, but those were mostly limited to PAF population or CPVI without linear ablation. ${ }^{14,15}$ In the current study, we focused on changes in $\mathrm{P}$ wave axis among ECG parameters, since a consistent linear ablation lesion set was performed in L-PeAF patients. Patients with L-PeAF could have an extraordinary amount of left atrial scar. These intrinsic left atrial scars can affect atrial conduction. However, use of the Dallas lesion set, which includes a posterior box lesion and anterior line, resulted in an inferior shift of the $\mathrm{P}$ wave axis. Especially, it was mainly related to the completeness of an anterior line in this study. An anterior line crosses the septopulmonary, septoatrial, and Bachmann's bundles, ${ }^{16}$ injuring these muscle fibers and changing interatrial conduction. ${ }^{17,18}$ An anterior linear ablation therefore results in significant changes in the LA activation pattern, mainly through septal activation and the crista terminalis. ${ }^{18,19}$ This shifts the sum of the atrial conduction vector more towards the inferior axis. ${ }^{20}$

\section{Prognostic value of the $P$ wave axis}

Recent studies suggest a prognostic value of the morphology of the $\mathrm{P}$ wave in terms of the clinical outcome after AF ablation. This prognostic value is mostly related to a pre-existent prolonged $\mathrm{P}$ wave duration and a reduced $\mathrm{P}$ wave amplitude, ${ }^{7,15}$ or less shortening of the post-procedural $\mathrm{P}$ wave duration. ${ }^{14}$ In this study, we found that the $\mathrm{P}$ wave axis change has a prognostic value after catheter ablation for L-PeAF, including anterior linear ablation. We postulated that there was a dependence of a prognostic value of the $\mathrm{P}$ wave axis inferior displacement on a degree of an anterior linear ablation completed. Pak et al. ${ }^{3}$ suggested the clinical usefulness of anterior linear ablation in patients with PeAF, related to blocking reentries around the mitral annulus, septum to roof, and left atrial appendage or critical mass reduction. Although we previously reported an easy anterior line generation and better clinical outcomes in comparison to the ones from PeAF left lateral isthmus ablation, an anterior line ablation long-term outcome remains yet to be clearly determined. In this study, long-term maintenance of a $\mathrm{P}$ wave axis inferior shift was closely related to remaining anterior line block and a low very late clinical recurrence of $\mathrm{AF}$ at one year after the procedure. The other potential explanation is that the patients with significant substrate remodeling had already developed a displaced $\mathrm{P}$ wave axis before the de novo procedure, and had a smaller change of $\mathrm{P}$ wave shift after the procedure. We previously reported that patients with atrial structural remodeling, displaced left atrial septal activation, and poor Bachmann's bundle conduction have higher chances of AF recurrence after catheter ablation. ${ }^{7}$ While the exact mechanism of this is not clear without repeated invasive mapping, it is encouraging to discover a sheer possibility of a simple noninvasive ECG parameter's (i.e., $P$ wave axis) role in estimating the maintenance of a conduction block or in approximating a longterm risk of very late clinical recurrence in L-PeAF patients who underwent catheter ablation, including an anterior line ablation. Further research involving multi-center studies on ECG analysis in a higher number of patients with L-PeAF is warranted.

\section{Limitations}

This was a single-center cohort study that included a selective group of patients referred for L-PeAF catheter ablation; therefore, its results cannot be generalized. A high percentage of patients had L-PeAF in our cohort. It was possible to have included some paroxysmal or persistent AF patients who only underwent ECGs when they were in atrial fibrillation, and who were actually in sinus rhythm most of the time between the ECGs. We included only those patients with L-PeAF who underwent RFCA with the same lesion set, including anterior line. However, few patients showed AF trigger or APC frequently on isoproterenol infusion after standard lesion set ablation, focus was searched and ablated. This might make the lesion set heterogeneous, but its effect on conduction was probably minimal as compared with linear ablation, since focal ablation was performed. Although we derived the importance of anterior line based on multivariate regression analyses, we cannot exclude the potential inter-dependence between anterior line and other linear lesions. In this study, we 
included the patients taking $\mathrm{AAD}$ in analyzing the role of $\mathrm{P}$ wave axis in predicting very late clinical recurrence of AF one year after catheter ablation. However, the result found was consistent with that among patients without $\mathrm{AAD}$.

\section{Conclusions}

An inferior shift of $\mathrm{P}$ wave axis reflects the achievement and maintenance of an anterior line $\mathrm{BDB}$, and tends to have a correlation with better long-term clinical outcomes following catheter ablation for L-PeAF.

\section{Conflict of interest}

The authors declare that they have no conflict of interest.

\section{Source of funding}

This research was supported by a grant (A085136) from the Korea Health 21 R\&D Project, Ministry of Health.

\section{References}

1) Kirchhof P, Benussi S, Kotecha D, Ahlsson A, Atar D, Casadei B, Castella M, Diener HC, Heidbuchel H, Hendriks J, Hindricks G, Manolis AS, Oldgren J, Popescu BA, Schotten U, Van Putte B, Vardas P, Agewall S, Camm J, Baron Esquivias G, Budts W, Carerj S, Casselman F, Coca A, De Caterina R, Deftereos S, Dobrev D, Ferro JM, Filippatos G, Fitzsimons D, Gorenek B, Guenoun M, Hohnloser SH, Kolh P, Lip GY, Manolis A, McMurray J, Ponikowski P, Rosenhek R, Ruschitzka F, Savelieva I, Sharma S, Suwalski P, Tamargo JL, Taylor CJ, Van Gelder IC, Voors AA, Windecker S, Zamorano JL, Zeppenfeld K. 2016 ESC Guidelines for the management of atrial fibrillation developed in collaboration with EACTS: the Task Force for the management of atrial fibrillation of the European Society of Cardiology (ESC): developed with the special contribution of the European Heart Rhythm Association (EHRA) of the ESC: endorsed by the European Stroke Organisation (ESO). Europace. 2016;18:16091678.

2) Wynn GJ, Das M, Bonnett LJ, Panikker S, Wong T, Gupta D. Efficacy of catheter ablation for persistent atrial fibrillation: a systematic review and meta-analysis of evidence from randomized and nonrandomized controlled trials. Circ Arrhythm Electrophysiol. 2014;7:841-852.

3) Pak HN, Oh YS, Lim HE, Kim YH, Hwang C. Comparison of voltage map-guided left atrial anterior wall ablation versus left lateral mitral isthmus ablation in patients with persistent atrial fibrillation. Heart Rhythm. 2011;8:199-206.

4) Edgerton JR, Jackman WM, Mahoney C, Mack MJ. Totally thorascopic surgical ablation of persistent AF and long-standing persistent atrial fibrillation using the "Dallas" lesion set. Heart Rhythm. 2009;6:S64-S70.

5) Tilz RR, Rillig A, Thum AM, Arya A, Wohlmuth P, Metzner A, Mathew S, Yoshiga Y, Wissner E, Kuck KH, Ouyang F. Catheter ablation of long-standing persistent atrial fibrillation: 5-year outcomes of the Hamburg Sequential Ablation Strategy. J Am Coll Cardiol. 2012;60:1921-1929.

6) European Heart Rhythm A, European Association for CardioThoracic S, Camm AJ, Kirchhof P, Lip GY, Schotten U, Savelieva I, Ernst S, Van Gelder IC, Al-Attar N, Hindricks G, Prendergast B, Heidbuchel H, Alfieri O, Angelini A, Atar D, Colonna P, De Caterina R, De Sutter J, Goette A, Gorenek B, Heldal M, Hohloser SH, Kolh P, Le Heuzey JY, Ponikowski P, Rutten FH. Guidelines for the management of atrial fibrillation: the Task Force for the Management of Atrial Fibrillation of the European Society of Cardiology (ESC). Eur Heart J. 2010;31:2369-2429.

7) Park JK, Park J, Uhm JS, Joung B, Lee MH, Pak HN. Low P-wave amplitude $(<0.1 \mathrm{mV})$ in lead $\mathrm{I}$ is associated with displaced interatrial conduction and clinical recurrence of paroxysmal atrial fibrillation after radiofrequency catheter ablation. Europace. 2016;18:384-391.

8) Park J, Kim TH, Lee JS, Park JK, Uhm JS, Joung B, Lee MH, Pak HN. Prolonged PR interval predicts clinical recurrence of atrial fibrillation after catheter ablation. J Am Heart Assoc. 2014;3:e001277.

9) Blanche C, Tran N, Rigamonti F, Burri H, Zimmermann M. Value of $\mathrm{P}$-wave signal averaging to predict atrial fibrillation recurrences after pulmonary vein isolation. Europace. 2013;15:198-204.

10) Park JH, Pak HN, Choi EJ, Jang JK, Kim SK, Choi DH, Choi JI, Hwang C, Kim YH. The relationship between endocardial voltage and regional volume in electroanatomical remodeled left atria in patients with atrial fibrillation: comparison of three-dimensional computed tomographic images and voltage mapping. J Cardiovasc 
Electrophysiol. 2009;20:1349-1356.

11) Kim TH, Park J, Park JK, Uhm JS, Joung B, Hwang C, Lee MH, Pak HN. Linear ablation in addition to circumferential pulmonary vein isolation (Dallas lesion set) does not improve clinical outcome in patients with paroxysmal atrial fibrillation: a prospective randomized study. Europace. 2015;17:388-395.

12) Calkins H, Kuck KH, Cappato R, Brugada J, Camm AJ, Chen SA, Crijns HJ, Damiano RJ Jr, Davies DW, DiMarco J, Edgerton J, Ellenbogen K, Ezekowitz MD, Haines DE, Haissaguerre M, Hindricks G, Iesaka Y, Jackman W, Jalife J, Jais P, Kalman J, Keane D, Kim YH, Kirchhof P, Klein G, Kottkamp H, Kumagai K, Lindsay BD, Mansour M, Marchlinski FE, McCarthy PM, Mont JL, Morady F, Nademanee K, Nakagawa H, Natale A, Nattel S, Packer DL, Pappone C, Prystowsky E, Raviele A, Reddy V, Ruskin JN, Shemin RJ, Tsao HM, Wilber D. 2012 HRS/EHRA/ECAS Expert consensus statement on catheter and surgical ablation of atrial fibrillation: recommendations for patient selection, procedural techniques, patient management and follow-up, definitions, endpoints, and research trial design. Europace. 2012;14:528-606.

13) Holmqvist F, Husser D, Tapanainen JM, Carlson J, Jurkko R, Xia Y, Havmöller R, Kongstad O, Toivonen L, Olsson SB, Platonov PG. Interatrial conduction can be accurately determined using standard 12-lead electrocardiography: validation of P-wave morphology using electroanatomic mapping in man. Heart
Rhythm. 2008;5:413-418.

14) Lim TW, Wu G, Ross DL, Thomas SP. P-wave measurements and electrical reconnection of the posterior left atrium after catheter ablation for atrial fibrillation. Pacing Clin Electrophysiol. 2010;33:1324-1334.

15) Ogawa M, Kumagai K, Vakulenko M, Yasuda T, Siegerman C, Garfinkel A, Chen PS, Saku K. Reduction of P-wave duration and successful pulmonary vein isolation in patients with atrial fibrillation. J Cardiovasc Electrophysiol. 2007;18:931-938.

16) Ho SY, Anderson RH, Sanchez-Quintana D. Atrial structure and fibres: morphologic bases of atrial conduction. Cardiovasc Res. 2002;54:325-336.

17) Ariyarajah V, Spodick DH. The Bachmann Bundle and interatrial conduction. Cardiol Rev. 2006;14:194-199.

18) Waldo AL, Bush HL, Jr., Gelband H, Zorn GL, Jr., Vitikainen KJ, Hoffman BF. Effects on the canine P wave of discrete lesions in the specialized atrial tracts. Circ Res. 1971;29:452-467.

19) Sanders P, Jais P, Hocini M, Hsu LF, Scavee C, Sacher F, Rotter M, Takahashi Y, Pasquié JL, Shah DC, Garrigue S, Clémenty J, Haïssaguerre M. Electrophysiologic and clinical consequences of linear catheter ablation to transect the anterior left atrium in patients with atrial fibrillation. Heart Rhythm. 2004;1:176-184.

20) Markides V, Schilling RJ, Ho SY, Chow AW, Davies DW, Peters NS. Characterization of left atrial activation in the intact human heart. Circulation. 2003;107:733-739. 